\title{
Capacitive behavior of functionalized activated carbon-based all-solid-state supercapacitor
}

\author{
Kyu Seok Lee ${ }^{1} \cdot$ Ye Ji Seo $^{1} \cdot$ Hyeon Taek Jeong ${ }^{1}$ (I)
}

Received: 14 September 2020 / Revised: 15 December 2020 / Accepted: 17 December 2020 / Published online: 12 January 2021

(c) The Author(s) 2021

\begin{abstract}
In this report, we incorporate activated carbon (AC) onto aluminum substrate via doctor blade method to produce an all-solid-state supercapacitor. The electrochemical properties of the all-solid-state supercapacitor were characterized by cyclic voltammetry and electrochemical impedance spectroscopy. Galvanostatic charge/discharge tests also were carried out to exhibit stability of the AC-based supercapacitor. The impedance and charge/discharge curves of the all-solid-state supercapacitor showed good capacitive behavior after functionalized AC. The highest specific capacitance obtained for the AC-based supercapacitor was $106 \mathrm{~F} \mathrm{~g}^{-1}$. About $160 \%$ of specific capacitance increased after functionalization of the AC, which indicated that modification of the AC by nitric acid was able to introduce functional groups on the AC and improve its electrochemical performances.
\end{abstract}

Keywords Activated carbon (AC) $\cdot$ Doctor blade method $\cdot$ All-solid-state supercapacitor $\cdot$ Functionalized activated carbon

\section{Introduction}

The development of energy storage devices is of great significance for applications in variable electronics [1]. Among the various energy storage devices available, electrochemical supercapacitors (ESCs) are promising candidates due to their high power density, long cycle life, durability and stability [2]. In addition, these types of ESCs are also desired for various applications, including portable devices, electric vehicles and energy storage system [3]. These applications require not only high capacitance for operation but also cycle stability. There are two types of ESCs depending on the charging mechanism. The first is the electrochemical double-layer capacitor (EDLC) which is based on the electric double layer that is formed at the interface between electrode and electrolyte [4]. The second type is pseudocapacitor based on Faradaic reaction that stores ions by inducing electron charge transfer at the bulk near surface of the electrode materials $[4,5]$.

Hyeon Taek Jeong

jht4321@daejin.ac.kr

1 Division of Energy and Environmental Engineering, Daejin University, 1007 Hoguk Road, Pocheon-si, Gyeonggi-do 487-711, South Korea
To develop technologies such as portable devices, nextgeneration displays and electric vehicles also demand the continued development of carbon-based active materials including, activated carbon (AC), graphene and carbon nanotube. $\mathrm{AC}$ is a suitable material for preparation of highperformance electrochemical supercapacitors due to their large surface area (1000-3000 $\left.\mathrm{m}^{2} \mathrm{~g}^{-1}\right)$ and low cost [6]. $\mathrm{AC}$ can be fabricated by physical/chemistry processes with common materials such as coconut [7], walnut shells [8], waste coffee beans [9], and bamboo [10]. On the other hand, the hydrophobic property of AC prevents the absorbing of electrolyte ions to the electrode interface. The surface modification method is one of the roots to overcome this issue to impart hydrophilic properties to activated carbon [11]. Lee et al. have reported that $\mathrm{AC}$ modified by oxyfluorination and showed maximum specific capacitance of $189 \mathrm{~F} \mathrm{~g}^{-1}$ at the scan rate of $50 \mathrm{mV} \mathrm{s}^{-1}$ [12]. Ji et al. doped multi-heteroatom on the AC surface through modification of AC by phosphoric acid. They also demonstrated a high-energy density of $35 \mathrm{~W} \mathrm{~h} \mathrm{~kg}^{-1}$ and high-operating voltage window of $1.9 \mathrm{~V}$ in $\mathrm{Na}_{2} \mathrm{SO}_{4}$ [13].

Polymer-based electrolytes are used in various energy storage devices such as lithium ion batteries and supercapacitors due to their characteristics including leakage prevention, mechanical stability, and flexibility [14]. There are two types of electrolyte called solid polymer electrolytes (SPEs) and gel 
polymer electrolytes (GPEs). SPEs have low ionic conductivity and poor interfacial contacts at electrode/electrolyte interface [14]. On the other hand, GPEs have wide potential range, high ionic conductivity of $10^{-4}$ to $10^{-2} \mathrm{~S} \mathrm{~cm}^{-1}$ is appropriate for flexible supercapacitor design due to the flexibility and role as a separator $[15,16]$. Lei et al. have prepared a flexible supercapacitor using PVA-KOH- $\mathrm{K}_{3}\left[\mathrm{Fe}(\mathrm{CN})_{6}\right]$ as a gel polymer electrolyte and separator as well which indicate the high specific capacitance of $430.95 \mathrm{~F} \mathrm{~g}^{-1}$ [17]. Ionic liquids have also attracted attention to substitute the organic solvents [18]. There are many reports on ionic liquid gel polymer electrolytes such as BMIMI [16], [PMpyr][NTf ${ }_{2}$ [ [19], EMImFAP [20] and $\mathrm{BMIBF}_{4}$ [21]. H. Su et al. constructed an supercapacitor with $\mathrm{EMIMBF}_{4}$-based gel polymer electrolyte and achieved high specific capacitance of $337 \mathrm{~F} \mathrm{~g}^{-1}$ at high operating voltage of $2.5 \mathrm{~V}$ [22].

In this work, we report on the preparation of an all-solidstate supercapacitor using a simple and inexpensive doctor blade method, which is potentially applicable at an industrial scale. AC was introduced and functionalized to increase its electrochemical property and coated onto aluminum foil to create an electrode. This is demonstrated through characterization of their electrochemical properties such as changes in specific capacitance after functionalization of the activated carbon. Polymer-based solid-state electrolyte also conducted to produce the all-solid-state supercapacitor. We also describe the surface morphology of functionalized activated carbon on the substrate.

\section{Experimental}

\subsection{Materials}

Polyvinyl alcohol (PVA) and 1-ethyl-3-methylimidazolium tetrafluoroborate $\left(\mathrm{EMIBF}_{4}\right)$ was obtained from Sigma Aldrich, Phosphoric acid $\left(\mathrm{H}_{3} \mathrm{PO}_{4}\right)$ was sourced from Duksan Pure Chemical to prepare gel polymer electrolyte. AC was purchased from Kansai Coke and Chemicals Co. Ltd and to use as an active material to prepare electrode. Carbon black (Super-P) was obtained from Imerys Graphite and Carbon and used to conducting additive for electrode slurry. Carboxymethyl cellulose (CMC) and BM-400B was sourced from Tokyo Chemical Industry Co., Ltd, and ZEON corporation to use as the binding materials. Nitric acid was purchased from Duksan pure chemical and D.I water was prepared from water purification system (pure power I+) with a resistivity up to $18.3 \mathrm{~m} \Omega \mathrm{cm}$, Human Corp., Korea.

\subsection{Preparation of activated carbon (AC) -based supercapacitor}

\subsubsection{Preparation of polymer-based solid-state electrolyte}

PVA $(1 \mathrm{~g})$ was added to D.I. water $(10 \mathrm{~mL})$ to create PVA solution with vigorous stirring at $80^{\circ} \mathrm{C}$ for $2 \mathrm{~h}$. $\mathrm{EMIBF}_{4}$ (ionic liquid (IL), $1 \mathrm{~g}$ ) was added into the PVA solution and stirred at $80{ }^{\circ} \mathrm{C}$ for $2 \mathrm{~h}$. Then, $\mathrm{H}_{3} \mathrm{PO}_{4}(1.6 \mathrm{~g})$ was poured into the PVA/IL solution, and stirred at $50{ }^{\circ} \mathrm{C}$ for $24 \mathrm{~h}$. Finally, the prepared PVA/IL/ $\mathrm{H}_{3} \mathrm{PO}_{4}$ solution was placed in desiccator to secure from moisture.

\subsubsection{Purification and functionalization of activated carbon (AC)}

Purification and functionalization of the AC were carried out to introduce functional groups such as hydroxyl group and carboxylic group by nitric acid treatment, which was able to improve electrochemical performance of the AC-based supercapacitor. Approximately $2 \mathrm{~g}$ of AC was refluxed in $60 \mathrm{~mL} 6 \mathrm{M}$ nitric acid for $12 \mathrm{~h}$, then filtered through a PTFE-coated polypropylene filter $(0.2 \mu \mathrm{m})$ and rinsed with deionized water. The final sample was dried for 1 day at $120^{\circ} \mathrm{C}$.

\subsubsection{Preparation of AC electrode slurry}

To prepare the electrode slurry, all materials including AC, Super-p, CMC and BM-400 were mixed by thinky mixer with ratio of 96.5 (AC):1.5 (Super-p): 1 (CMC):1 (BM-400) at $2000 \mathrm{rpm}$. First, AC was dispersed in distilled water for $10 \mathrm{~min}$. Then, $\mathrm{CMC}$ was added into the $\mathrm{AC}$ solution and mixed for $5 \mathrm{~min}$. After that, super-P was added into the AC/CMC mixture solution and dispersed for 5 min. Finally, BM-400B was added into the AC/CMC/ super-p solution and dispersed for $5 \mathrm{~min}$. The acid-treated AC-based slurry also prepared through the same process.

\subsubsection{Fabrication of the electrode and activated carbon-based supercapacitor}

Figure 1 illustrates the procedure used to prepare AC and acid-treated AC-based supercapacitor. The prepared aluminum foil was washed with ethanol and flattened (step 1), then electrode slurry was coated on the aluminum foil by doctor blade-coating method (step 2). Coated aluminum foil was cut into $1 \mathrm{~cm}$ width with $4 \mathrm{~cm}$ length (step 3 ). The electrode was soaked in the gel polymer electrolyte by deep-coating method for $30 \mathrm{~min}$ and placed in room temperature until electrolyte dried (step 4). Finally, two 


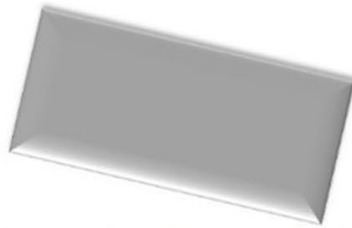

Preparation of Aluminum foil Step 1
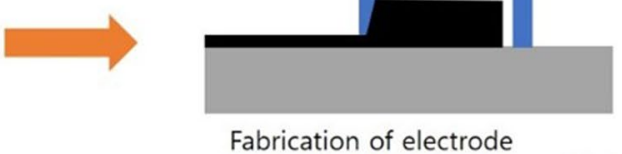

by doctor blade coating method

Step 2

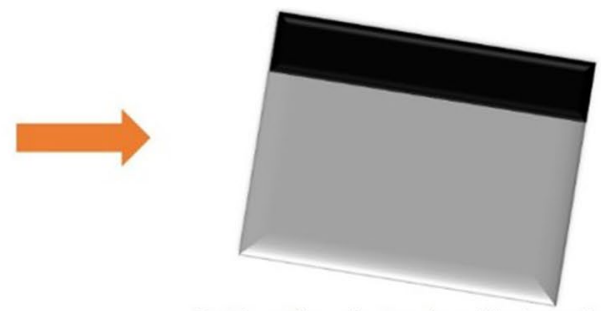

Cutting the electrode with $1 \mathrm{~cm} \times 4 \mathrm{~cm}$ Step 3
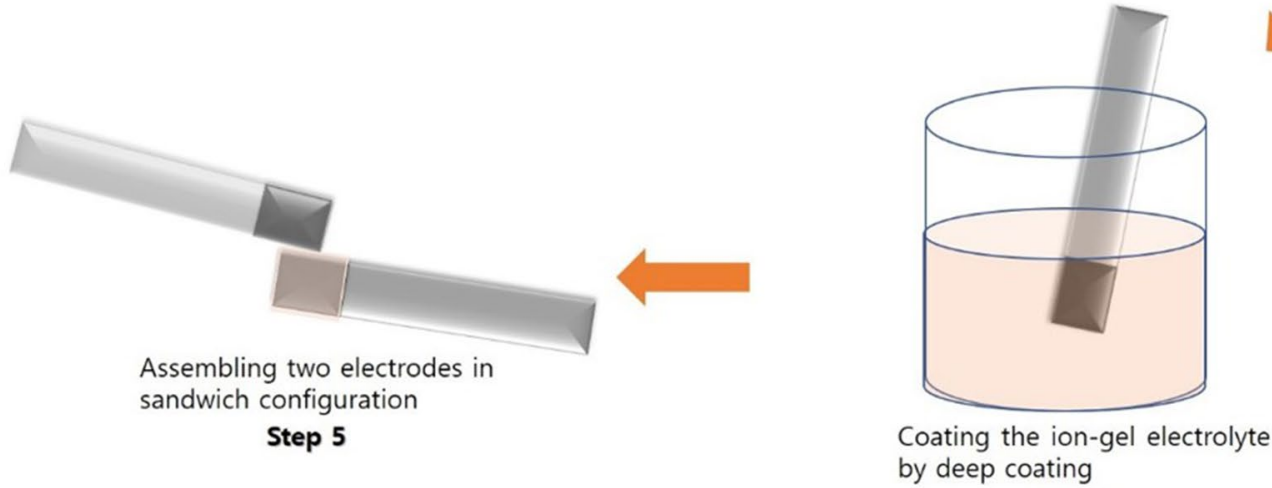

Step 4

Fig. 1 Preparation of the activated carbon (AC) -based all-solid-state supercapacitor via doctor blade method

electrodes were assembled in sandwich configuration to produce all-solid-state supercapacitor.

\section{Characterization}

\subsection{Morphology measurement of the activated carbon (AC) -based electrodes}

Surface morphology of the samples was obtained using a scanning electron microscopy with energy-dispersive X-ray spectrometry (XL30-SFEG \& Falco CDU). The accelerating voltage was $20.0 \mathrm{kV}$ and the emission current was 88 $\mu \mathrm{A}$. Fourier Transform Infrared Spectroscopy (FT-IR) were detected by FT-IR 460 plus. The spectra were obtained in the range of $1000-4000 \mathrm{~cm}^{-1}$. Due to high absorbance of the $\mathrm{AC}$ and acid-treated $\mathrm{AC}, \mathrm{KBr}$ pellets have been fabricated to the mass ratio of 500:1.

\subsection{Electrochemical properties of the activated carbon (AC) -based supercapacitor}

\subsubsection{Cyclic voltammetry (CV)}

Cyclic Voltammetry (CV) measurements of AC full device and acid-treated $\mathrm{AC}$ full device were performed at room temperature with two-electrode system using an ZIVE SP2 electrochemical workstation (ZIVE LAB). All the CV measurements were recorded by scan rate range of $5-100 \mathrm{mV} \mathrm{s}^{-1}$ with potential range $0-1 \mathrm{~V}$. The specific capacitance was calculated on the basis of the following equation [23]:

$C s p=\frac{\int I d V}{2 \times v \times m \times \Delta V}$

where $C_{s p}$ is the specific capacitance of the supercapacitor, $I$ is the instantaneous current, $\Delta V$ is the potential window width, $m$ is the mass of active material, $\nu$ is the potential scan rate and $\int I d V$ is the total voltammetric charge obtained by integration of the positive and negative sweep in cyclic voltammograms. Energy density and power density are derived from the following equations [24]:

$E=\frac{1}{2} C V^{2}$

$\mathrm{P}=\frac{E}{v}$

\subsubsection{Electrochemical impedance spectroscopy (EIS)}

Electrochemical impedance spectroscopy (EIS) was used to probe the resistance at the electrode/electrolyte interface and diffusion of ions in electrolyte. EIS 
measurements were performed at room temperature using a ZIVE SP2 electrochemical workstation (ZIVE LAB) where the frequency range spanned $100 \mathrm{kHz}$ to $0.01 \mathrm{~Hz}$ with an amplitude of $1 \mathrm{mV}$ (rms) at open circuit potential.

\subsubsection{Charge and discharge measurement}

A pair of each AC and acid-treated AC-based supercapacitor was performed using a ZIVE SP2 electrochemical workstation (ZIVE LAB) between 0 and $1 \mathrm{~V}$ voltage with current density $0.5-5 \mathrm{~A} \mathrm{~g}^{-1}$. The cycle stability was measured by 3000 charge/discharge cycle in room temperature.

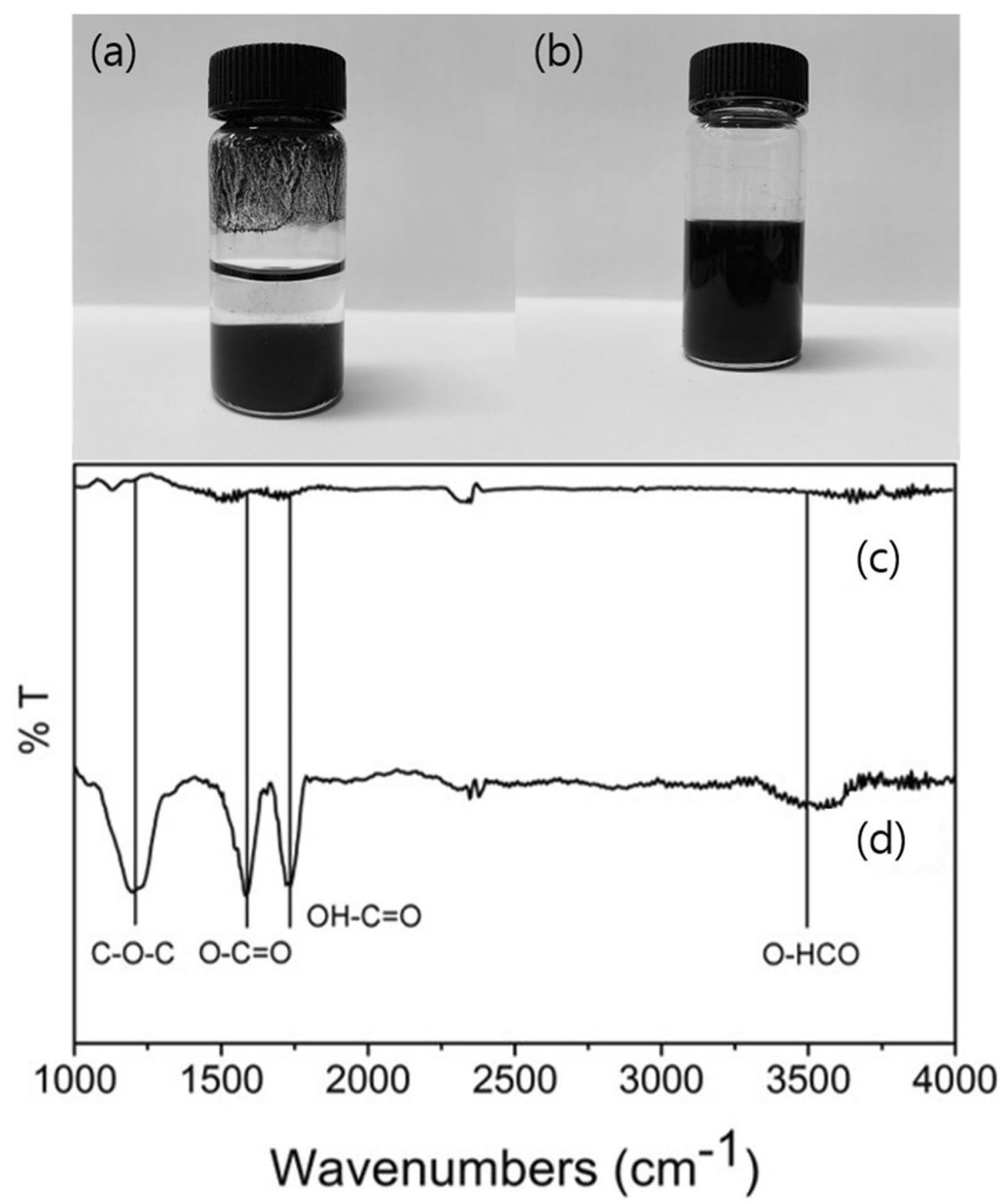

Fig. 2 Photograph of $\mathbf{a}$ activated carbon (AC) and $\mathbf{b}$ functionalized activated carbon (AC) dispersion with sonication for 1 h. FT-IR spectrum of $\mathbf{c}$ the pristine $\mathrm{AC}$ and $\mathbf{d}$ functionalized $\mathrm{AC}$ 


\section{Results and discussion}

The introduction of functional groups on the $\mathrm{AC}$ was confirmed by FT-IR spectroscopy (Fig. 2). In Fig. 2d, the carbonyl group stretch of the carboxylate anions appears at
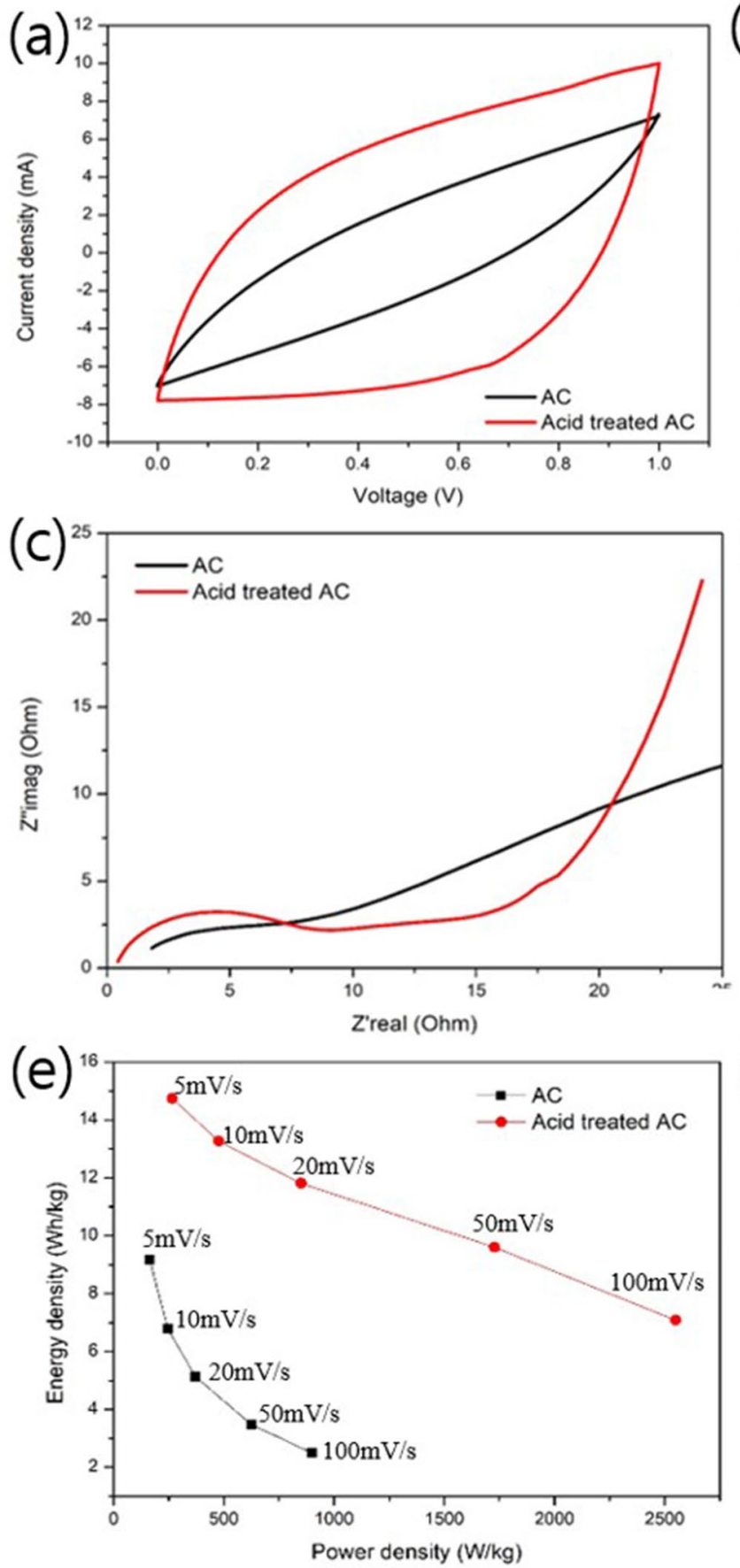

Fig. 3 Comparison of the electrochemical performances with pristine activated carbon (AC) and functionalized AC-based supercapacitor; a cyclic voltammetry $(\mathrm{CV}), \mathbf{b}$ electrochemical impedance spectroscopy
$1581 \mathrm{~cm}^{-1}$ for the acid-treated AC. The peaks at $3428 \mathrm{~cm}^{-1}$ and $1736 \mathrm{~cm}^{-1}$ were also from the $\mathrm{O}-\mathrm{HCO}$ stretch of the carboxylic acid groups, which indicated that the functional groups on the AC was introduced by acid treatment. On the other hand, the peaks on the acid-treated AC were not observed in the graph of pristine AC (Fig. 2c).
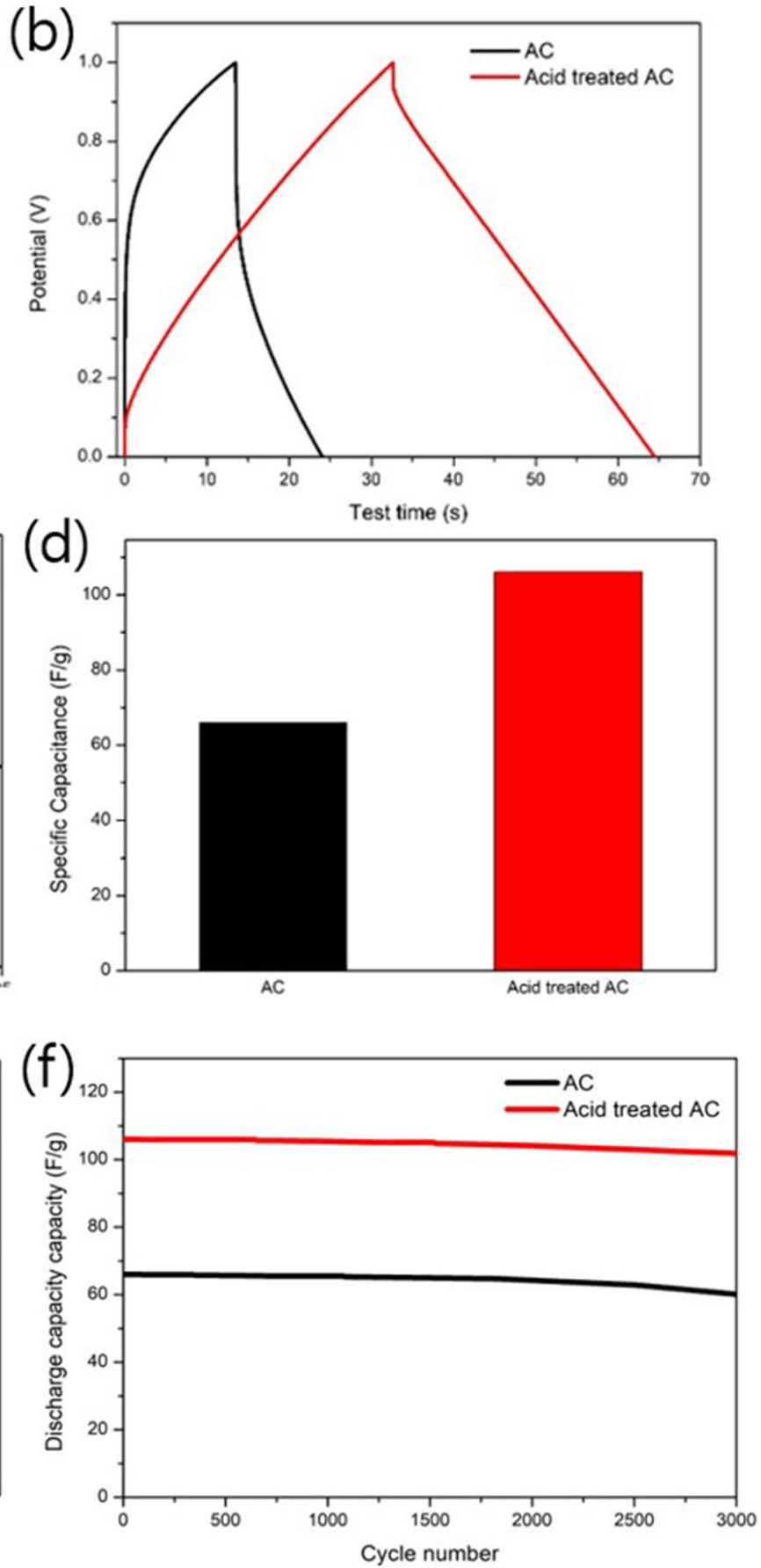

(EIS), c charge/discharge test, $\mathbf{d}$ specific capacitance, e energy and power density, and $\mathbf{f}$ cycle stability 
Figure 3 represents the electrochemical performances of $\mathrm{AC}$ and acid-treated AC-based supercapacitor through CV and EIS measurements. The CV curve of the acid-treated AC-based supercapacitor showed quasi-rectangular shape and large current area rather than AC-based supercapacitor (Fig. 3a). This means that acid-treated AC-based supercapacitor showed enhanced electroactive area which attributed to the improvement of charge storage capability, for the acid-treated AC-based supercapacitor [25]. Figure 3b shows the Nyquist plot of AC and acid-treated AC-based supercapacitor. Acid-treated AC-based supercapacitor exhibited not only a small semi-circle region but also low internal resistance compared to AC-based supercapacitor. It might be expected that the electrochemical properties of AC have been improved through surface modification and functionalization of the AC $[11,25]$. Figure $3 \mathrm{c}$ illustrates the GCD measurement of acid-treated AC-based supercapacitor. As a result, the acid-treated AC-based supercapacitor showed symmetric charge/discharge graph and enhanced charge/discharge time, which indicated the improved electrochemical properties of the acid-treated-based supercapacitor even for small IR drop on the graph. This result also corresponded to the CV and EIS graphs.

The specific capacitance is derived from Eq. (1). The specific capacitance of the acid-treated AC-based supercapacitor was $106 \mathrm{Fg}^{-1}$ while the $\mathrm{AC}$-based supercapacitor showed $66 \mathrm{~F} \mathrm{~g}^{-1}$ (Fig. 4d). The maximum power density of the acidtreated AC-based supercapacitor was $2.5 \mathrm{~kW} \mathrm{~kg}^{-1}$ at scan rate of $100 \mathrm{mV} \mathrm{s}^{-1}$. On the other hand, the AC-based supercapacitor was only $0.9 \mathrm{~kW} \mathrm{~kg}^{-1}$ (Fig. 4e). The cycle stability of functionalized $\mathrm{AC}$ was $95 \%$, while the pristine $\mathrm{AC}$ was 90\% (Fig. 4f). This results indicated that acid-treated ACbased supercapacitor showed excellent cycle stability in the charge/discharge process due to its large surface area and hydrophilic properties which decreased resistance between electrode/electrolyte interface [26]. (a)

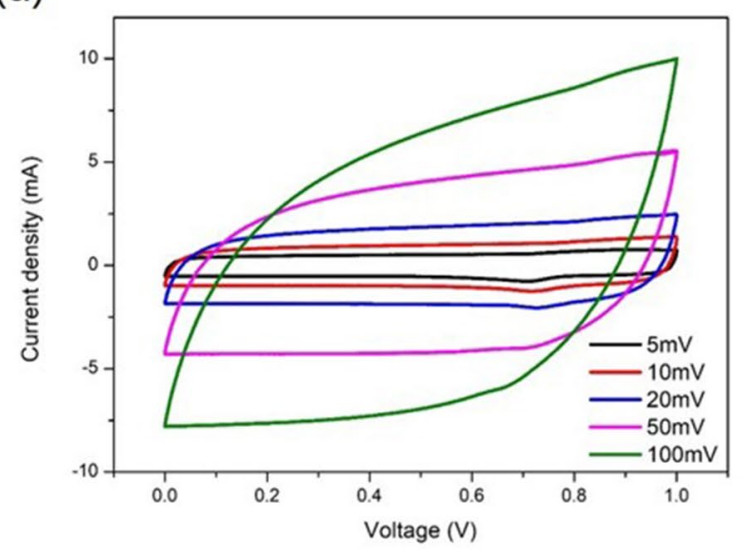

(c)

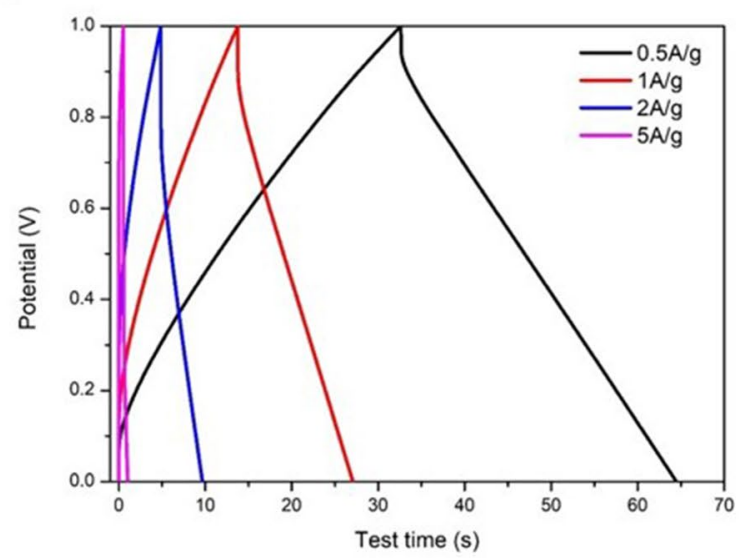

(b)

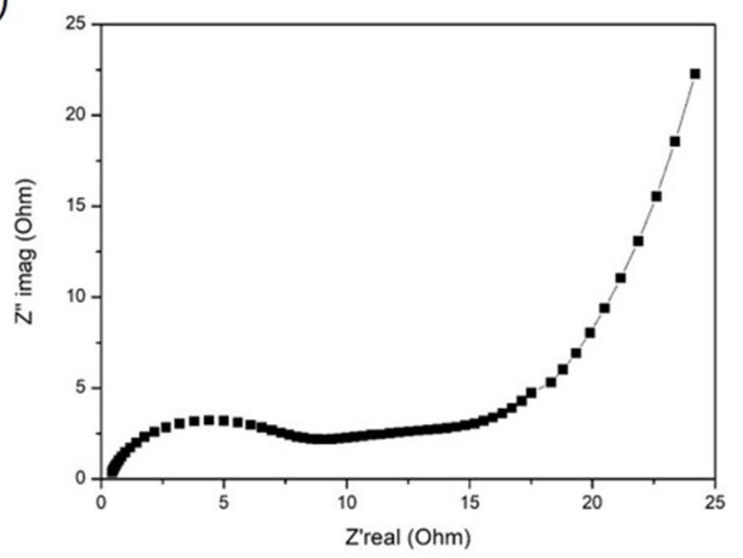

(d)

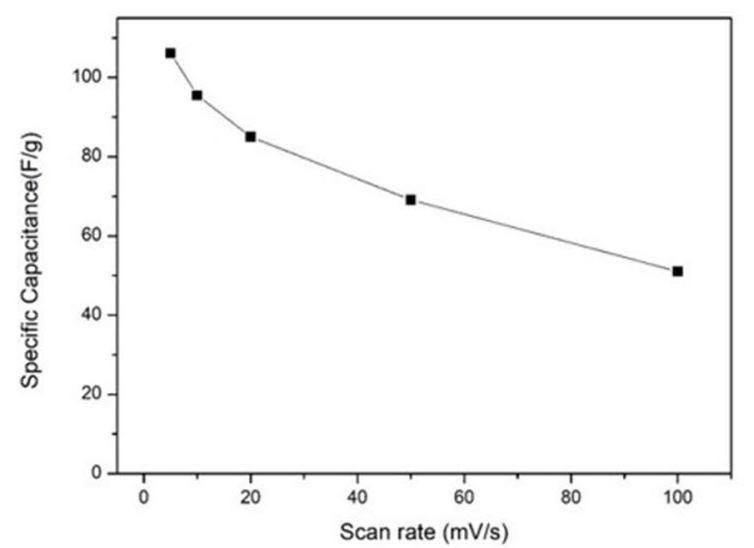

Fig. 4 Electrochemical properties of the functionalized activated carbon (AC) -based supercapacitor at varying condition. a Cyclic voltammetry (CV), b electrochemical impedance spectroscopy (EIS), c charge/discharge test, and d specific capacitance at different scan rate 
We have also investigated CV, EIS, GCD and $\mathrm{C}_{\mathrm{sp}}$ of the acid-treated AC-based supercapacitor. All the CV curves of the acid-treated AC-based supercapacitor showed quasirectangular shape (Fig. 4a), which indicated that the acidtreated $\mathrm{AC}$ had an ideal electrochemical performance and excellent reversibility [27]. Figure $4 \mathrm{~b}$ shows a low resistance value of $0.4 \Omega$ with small semi-circle in the high frequency. At a low frequency, the line slope was increased which indicated low diffusivity resistance [28]. Figure 4c displays the charge/discharge curves of the acid-treated AC-based supercapacitor within the potential range 0-1 V at different current density from 0.5 to $5 \mathrm{~A} \mathrm{~g}^{-1}$. All lines showed symmetric charge/discharge graph, indicating the enhanced capacitive behavior of the acid-treated AC-based supercapacitor [29]. The specific capacitance was increased with respect to increase scan rate $\left(106 \mathrm{~F} \mathrm{~g}^{-1}, 95 \mathrm{~F} \mathrm{~g}^{-1}\right.$, $85 \mathrm{~F} \mathrm{~g}^{-1}, 69 \mathrm{~F} \mathrm{~g}^{-1}$, and $51 \mathrm{~F} \mathrm{~g}^{-1}$ at the scan rate of $5 \mathrm{mV} \mathrm{s}^{-1}$, $10 \mathrm{mV} \mathrm{s}^{-1}, 20 \mathrm{mV} \mathrm{s}^{-1}, 50 \mathrm{mV} \mathrm{s}^{-1}$, and $100 \mathrm{mV} \mathrm{s}^{-1}$ ), which might be due to the lack of charge/discharge time at high scan rate [30].

The SEM-EDS images of pristine AC and acid-treated $\mathrm{AC}$ are shown in Fig. 5. The SEM images showed that $\mathrm{HNO}_{3}$ had an effect on the surface corrosion of activated carbon (Fig. 5a, b). The EDS data indicated that the oxygen content of acid-treated AC increased after functionalization while the carbon content decreased (Fig. 5c, d). The increased oxygen content indicated that a strong interaction between the active material and the electrolyte is imparted by introducing a hydrophilic group to the AC [11].

\section{Conclusion}

The physical properties of the pristine and acid-treated AC were characterized by FT-IR, and SEM. Particle size of the AC was measured by field emission scanning electron microscopy before and after functionalization of the AC. Three peaks were seen at $1581 \mathrm{~cm}^{-1}, 1736 \mathrm{~cm}^{-1}$, and $3428 \mathrm{~cm}^{-1}$ by FT-IR spectroscopy which represented the carbonyl groups stretch of the carboxylate anions and carboxylic acid, respectively. In addition, acid-treated ACbased supercapacitor was successfully fabricated using a doctor blade-coating method. The acid-treated AC-based supercapacitor showed capacitive current in cyclic voltammograms, indicating typical capacitive behavior under various scan rate. The highest capacitance value obtained for acid-treated AC-based supercapacitor was $106 \mathrm{~F} \mathrm{~g}^{-1}$ in $\mathrm{PVA} / \mathrm{H}_{3} \mathrm{PO}_{4} / \mathrm{EMIBF}_{4}$ electrolyte at $5 \mathrm{mV} \mathrm{s}{ }^{-1}$. Acid-treated
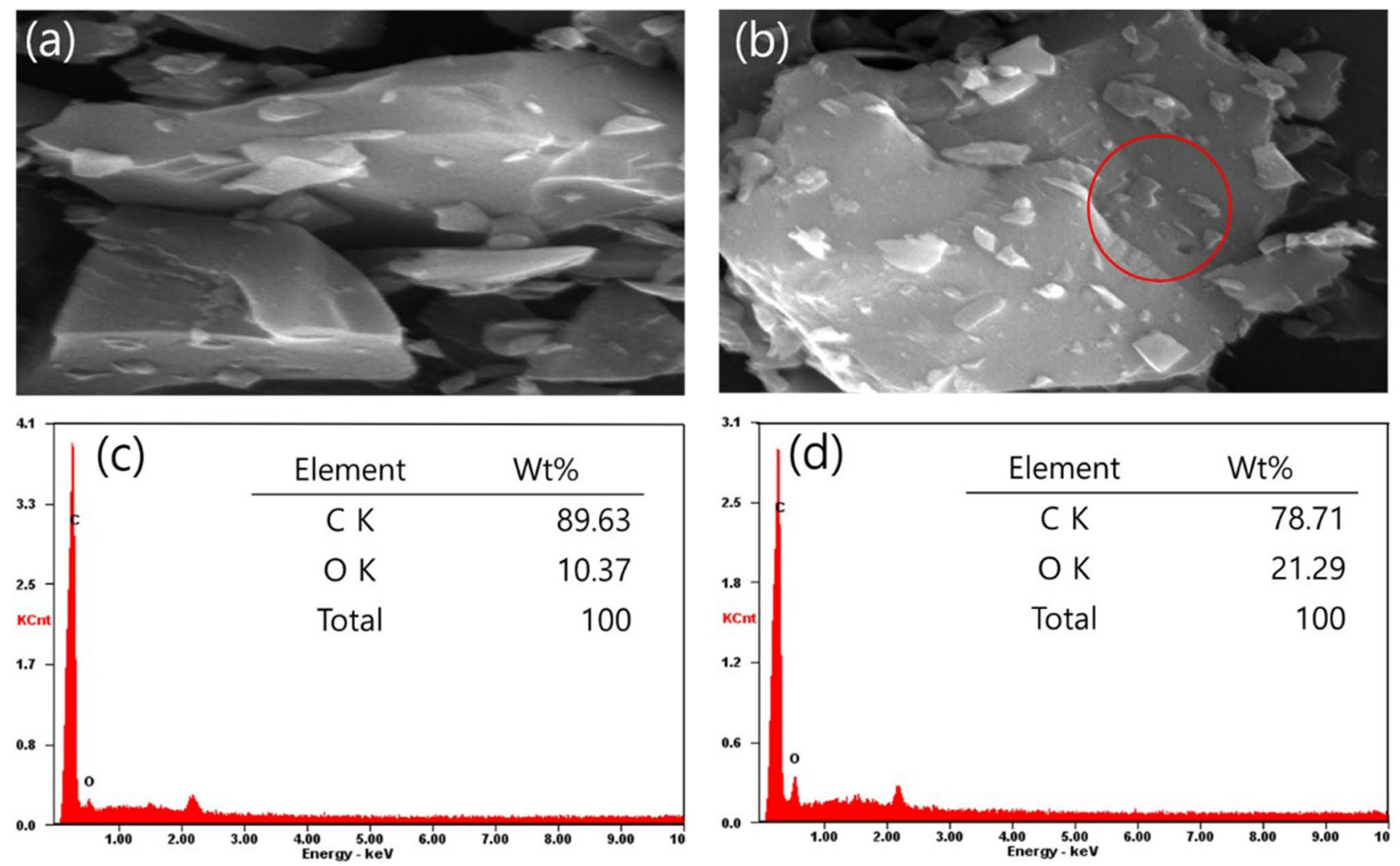

Fig. 5 SEM-EDS images of the a activated carbon (AC), b functionalized activated carbon (AC), $\mathbf{c}$ EDS of AC, and $\mathbf{d}$ EDS of functionalized $\mathrm{AC}$ 
AC-based supercapacitor showed a high cycle stability of 95\% after 3000 charge/discharge cycle. We demonstrated that the modification of activated carbon with nitric acid showed better electrochemical performance.

Acknowledgements This work was supported by the National Research Foundation of Korea (NRF) grant funded by the Korea government (MSIT) (No. 2019R1F1A105946912).

\section{Compliance with ethical standards}

Conflict of interest The authors declare that they have no conflict of interest.

Open Access This article is licensed under a Creative Commons Attribution 4.0 International License, which permits use, sharing, adaptation, distribution and reproduction in any medium or format, as long as you give appropriate credit to the original author(s) and the source, provide a link to the Creative Commons licence, and indicate if changes were made. The images or other third party material in this article are included in the article's Creative Commons licence, unless indicated otherwise in a credit line to the material. If material is not included in the article's Creative Commons licence and your intended use is not permitted by statutory regulation or exceeds the permitted use, you will need to obtain permission directly from the copyright holder. To view a copy of this licence, visit http://creativecommons.org/licenses/by/4.0/.

\section{References}

1. Joo H, Han H, Cho S (2020) Fabrication of poly(vinyl alcohol)polyaniline nanofiber/graphene hydrogel for high-performance coin cell supercapacitor. Polymers 12 (4). doi:https://doi. org/10.3390/polym12040928

2. Zhao B, Chen D, Xiong X, Song B, Hu R, Zhang Q, Rainwater BH, Waller GH, Zhen D, Ding Y, Chen Y, Qu C, Dang D, Wong C-P, Liu M (2017) A high-energy, long cycle-life hybrid supercapacitor based on graphene composite electrodes. Energy Storage Mater 7:32-39. https://doi.org/10.1016/j.ensm.2016.11.010

3. Lee DY, Shinde DV, Kim E-K, Lee W, Oh I-W, Shrestha NK, Lee JK, Han S-H (2013) Supercapacitive property of metalorganic-frameworks with different pore dimensions and morphology. Microporous Mesoporous Mater 171:53-57. https://doi. org/10.1016/j.micromeso.2012.12.039

4. Sathyamoorthi S, Sawangphruk M (2019) A simple and practical hybrid ionic liquid/aqueous dual electrolyte configuration for safe and ion-exchange membrane-free high cell potential supercapacitor. Electrochim Acta 305:443-451. https://doi.org/10.1016/j.elect acta.2019.03.090

5. Liu YX, Wang YZ, Wang HQ, Zhao PH, Hou H, Guo L (2019) Acetylene black enhancing the electrochemical performance of NiCo-MOF nanosheets for supercapacitor electrodes. Appl Surf Sci 492:455-463. https://doi.org/10.1016/j.apsusc.2019.06.238

6. Sudhan N, Subramani K, Karnan M, Ilayaraja N, Sathish M (2017) Biomass-derived activated porous carbon from rice straw for a high-energy symmetric supercapacitor in aqueous and nonaqueous electrolytes. Energy Fuels 31(1):977-985. https://doi. org/10.1021/acs.energyfuels.6b01829

7. Mi J, Wang X-R, Fan R-J, Qu W-H, Li W-C (2012) Coconutshell-based porous carbons with a tunable micro/mesopore ratio for high-performance supercapacitors. Energy Fuels 26(8):53215329. https://doi.org/10.1021/ef3009234
8. Xu X, Gao J, Tian Q, Zhai X, Liu Y (2017) Walnut shell derived porous carbon for a symmetric all-solid-state supercapacitor. Appl Surf Sci 411:170-176. https://doi.org/10.1016/j.apsus c.2017.03.124

9. Rufford TE, Hulicova-Jurcakova D, Zhu Z, Lu GQ (2008) Nanoporous carbon electrode from waste coffee beans for high performance supercapacitors. Electrochem Commun 10(10):1594-1597. https://doi.org/10.1016/j.elecom.2008.08.022

10. Zhang GX, Chen YM, Chen YG, Guo HB (2018) Activated biomass carbon made from bamboo as electrode material for supercapacitors. Mater Res Bull 102:391-398. https://doi.org/10.1016/j. materresbull.2018.03.006

11. Zhang S, Shi X, Wróbel R, Chen X, Mijowska E (2019) Low-cost nitrogen-doped activated carbon prepared by polyethylenimine (PEI) with a convenient method for supercapacitor application. Electrochim Acta 294:183-191. https://doi.org/10.1016/j.elect acta.2018.10.111

12. Jung M-J, Jeong E, Lim JW, Lee SI, Lee Y-S (2011) Physicochemical surface modification of activated carbon by oxyfluorination and its electrochemical characterization. Colloids Surf A 389(1):274-280. https://doi.org/10.1016/j.colsurfa.2011.08.013

13. Deng Y, Ji Y, Wu H, Chen F (2019) Enhanced electrochemical performance and high voltage window for supercapacitor based on multi-heteroatom modified porous carbon materials. Chem Commun 55(10):1486-1489. https://doi.org/10.1039/C8CC08391F

14. Yadav N, Mishra K, Hashmi SA (2017) Optimization of porous polymer electrolyte for quasi-solid-state electrical double layer supercapacitor. Electrochim Acta 235:570-582. https://doi. org/10.1016/j.electacta.2017.03.101

15. Zhong J, Fan L-Q, Wu X, Wu J-H, Liu G-J, Lin J-M, Huang M-L, Wei Y-L (2015) Improved energy density of quasi-solidstate supercapacitors using sandwich-type redox-active gel polymer electrolytes. Electrochim Acta 166:150-156. https://doi. org/10.1016/j.electacta.2015.03.114

16. Tu Q-M, Fan L-Q, Pan F, Huang J-L, Gu Y, Lin J-M, Huang M-L, Huang Y-F, Wu J-H (2018) Design of a novel redox-active gel polymer electrolyte with a dual-role ionic liquid for flexible supercapacitors. Electrochim Acta 268:562-568. https://doi. org/10.1016/j.electacta.2018.02.008

17. Ma G, Li J, Sun K, Peng H, Mu J, Lei Z (2014) High performance solid-state supercapacitor with PVA-KOH-K3[Fe(CN)6] gel polymer as electrolyte and separator. J Power Sources 256:281-287. https://doi.org/10.1016/j.jpowsour.2014.01.062

18. Alipoori S, Mazinani S, Aboutalebi SH, Sharif F (2020) Review of PVA-based gel polymer electrolytes in flexible solid-state supercapacitors: Opportunities and challenges. J Energy Storage 27:101072. https://doi.org/10.1016/j.est.2019.101072

19. Muchakayala R, Song S, Wang J, Fan Y, Bengeppagari M, Chen J, Tan M (2018) Development and supercapacitor application of ionic liquid-incorporated gel polymer electrolyte films. J Ind Eng Chem 59:79-89. https://doi.org/10.1016/j.jiec.2017.10.009

20. Pandey GP, Hashmi SA (2013) Performance of solid-state supercapacitors with ionic liquid 1-ethyl-3-methylimidazolium tris(pentafluoroethyl) trifluorophosphate based gel polymer electrolyte and modified MWCNT electrodes. Electrochim Acta 105:333-341. https://doi.org/10.1016/j.electacta.2013.05.018

21. Obeidat AM, Gharaibeh MA, Obaidat M (2017) Solid-state supercapacitors with ionic liquid gel polymer electrolyte and polypyrrole electrodes for electrical energy storage. J Energy Storage 13:123-128. https://doi.org/10.1016/j.est.2017.07.010

22. Yadav N, Hashmi SA (2020) Energy enhancement of quasi-solidstate supercapacitors based on a non-aqueous gel polymer electrolyte via a synergistic effect of dual redox additives diphenylamine and potassium iodide. J Mater Chem A 8(35):18266-18279. https ://doi.org/10.1039/D0TA06331B 
23. Hu Z, Zu L, Jiang Y, Lian H, Liu Y, Li Z, Chen F, Wang X, Cui X (2015) High specific capacitance of polyaniline/mesoporous manganese dioxide composite using KI-H2SO4 electrolyte. Polymers 7 (10). doi:https://doi.org/10.3390/polym7101491

24. Peng S, Jiang X, Xiang X, Chen K, Chen G, Jiang X, Hou L (2019) High-performance and flexible solid-state supercapacitors based on high toughness and thermoplastic poly(vinyl alcohol)/NaCl/ glycerol supramolecular gel polymer electrolyte. Electrochim Acta 324:134874. https://doi.org/10.1016/j.electacta.2019.134874

25. Liu Y, Hu Z, Xu K, Zheng X, Gao Q (2008) Surface modification and performance of activated carbon electrode material. Acta Phys Chim Sin 24(7):1143-1148. https://doi.org/10.1016/S1872 -1508(08)60049-2

26. Elaiyappillai E, Srinivasan R, Johnbosco Y, Devakumar P, Murugesan K, Kesavan K, Johnson PM (2019) Low cost activated carbon derived from Cucumis melo fruit peel for electrochemical supercapacitor application. Appl Surf Sci 486:527-538. https:// doi.org/10.1016/j.apsusc.2019.05.004

27. Dong D, Zhang Y, Xiao Y, Wang T, Wang J, Romero CE, Pan W-p (2020) High performance aqueous supercapacitor based on nitrogen-doped coal-based activated carbon electrode materials. J Colloid Interface Sci 580:77-87. https://doi.org/10.1016/j. jcis.2020.07.018
28. Lee EJ, Lee YJ, Kim JK, Lee M, Yi J, Yoon JR, Song JC, Song IK (2015) Oxygen group-containing activated carbon aerogel as an electrode material for supercapacitor. Mater Res Bull 70:209-214. https://doi.org/10.1016/j.materresbull.2015.04.044

29. Yan J, Shen J, Li L, Ma X-K, Cui J-H, Wang L-Z, Zhang Y (2020) Template-like N, S and O tri-doping activated carbon derived from helianthus pallet as high-performance material for supercapacitors. Diam Relat Mater 102:107693. https://doi.org/10.1016/j. diamond.2019.107693

30. Ji Z, Li N, Xie M, Shen X, Dai W, Liu K, Xu K, Zhu G (2020) High-performance hybrid supercapacitor realized by nitrogendoped carbon dots modified cobalt sulfide and reduced graphene oxide. Electrochim Acta 334:135632. https://doi.org/10.1016/j. electacta.2020.135632

Publisher's Note Springer Nature remains neutral with regard to jurisdictional claims in published maps and institutional affiliations. 